\title{
Impact of health education on community knowledge, attitudes and behaviour towards solid waste management in Al Ghobeiry, Beirut
}

N. Karout ${ }^{7}$ and S. Altuwaijri' ${ }^{2}$

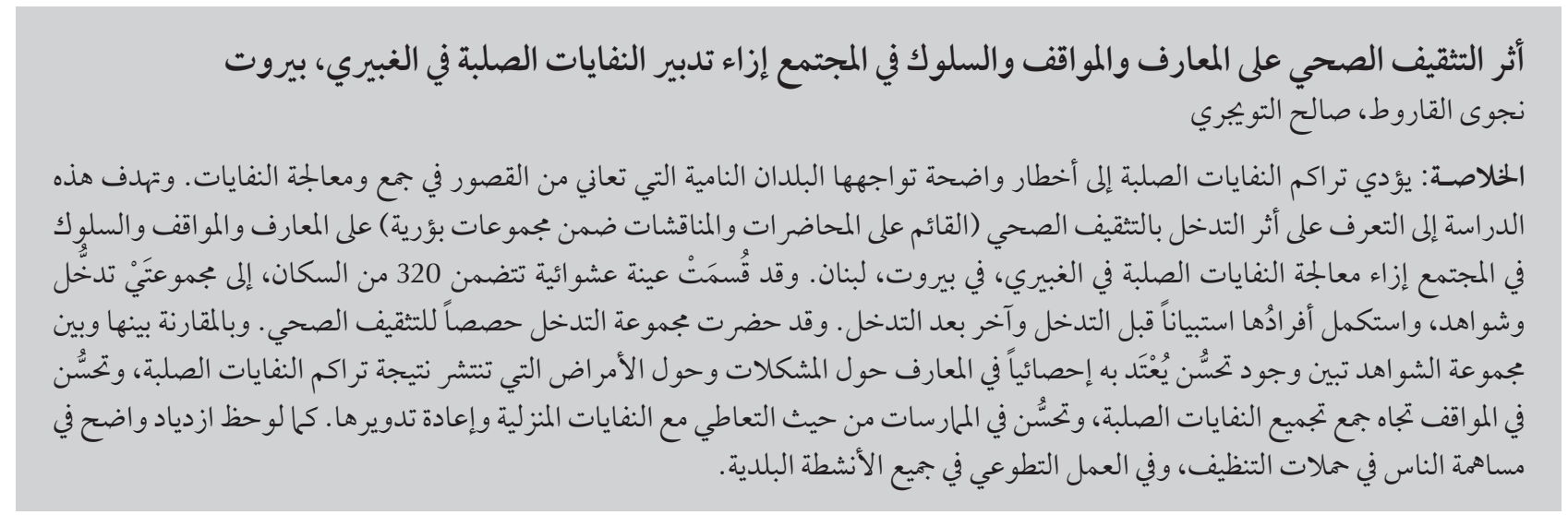

ABSTRACT The risks posed by accumulation of solid waste are most obvious in developing countries, where waste collection and treatment is often inadequate. This study aimed to determine the impact of a health education intervention (based on lectures and focus group discussions) on community knowledge, attitudes and behaviours concerning solid waste management in Al Ghobeiry, Beirut. A randomly selected sample of 320 inhabitants were divide into intervention and control groups who completed the same questionnaire in the pre- and post-intervention phases. Compared with the control group the intervention group, who attended the health education sessions, showed: significantly better knowledge about the problems of and diseases spread by accumulation of solid waste; better attitudes to management of solid waste collection; and improved practices in terms of handling and recycling of household waste. There was an observed increased participation by people in cleaning campaigns and voluntary work in all the municipality activities.

Impact de l'éducation sanitaire sur les connaissances, les attitudes et les comportements de la communauté en termes de gestion des déchets solides, Al Ghobeiry (Beyrouth)

RÉSUMÉ Les risques posés par l'accumulation de déchets solides sont criants dans les pays en développement où le ramassage des déchets et leur traitement sont fréquemment inadéquats. La présente étude visait à déterminer l'impact d'une intervention d'éducation sanitaire (composée de conférences et de groupes de discussions thématiques) sur les connaissances de la communauté en termes de gestion des déchets solides, ainsi que sur leurs attitudes et comportements en la matière à Al Ghobeiry (Beyrouth). Un échantillon de 320 habitants a été sélectionné aléatoirement puis réparti soit dans un groupe bénéficiant d'une intervention, soit dans un groupe témoin. Les deux groupes ont rempli le même questionnaire au cours des phases précédant et suivant l'intervention. Par rapport au groupe témoin, le groupe ayant bénéficié d'une intervention sous la forme de sessions d'éducation sanitaire a présenté les caractéristiques suivantes : des connaissances nettement supérieures sur les problèmes causés par l'accumulation de déchets solides et notamment les maladies qu'ils propagent; des attitudes plus positives à l'égard du ramassage des déchets solides; et des pratiques améliorées en termes de stockage et de recyclage des déchets ménagers. La participation des habitants aux campagnes de nettoyage et aux travaux volontaires proposés par les municipalités s'est accrue. 


\section{Introduction}

Globally, the waste management sector is facing numerous challenges. At present, a staggering 3.4-4 billion tons of municipal and industrial solid waste and up to 300 million tons of hazardous waste is annually produced worldwide [1]. As the volumes and complexity increase, the environmental risks posed by the waste sector-including human health risks, ecosystem degradation, contamination of soils and water, as well as greenhouse gas emissions - also become more serious. These risks are most obvious in developing countries where waste collection and treatment is typically insufficient or even absent [2].

Municipal solid waste (MSW) makes up more than $80 \%$ of the total solid waste stream generated in Lebanon. The main sources of solid waste are households, commercial establishments, restaurants, hotels, street markets and street cleaning operations [3]. Currently, Lebanon lacks any comprehensive strategy or efficient system to handle industrial and hazardous waste. [4]. In 2009 Lebanon generated about 1.57 million tons of MSW, and this is expected increase by an estimated $1.65 \%$ per year to reach 1.92 million tons by 2020 [3]. The practice of open burning of MSW and old tyres, generates a number of air pollutants and pathogens, while open dumpsites spread bacteria and vectorborne diseases through rats, flies and insects, and also produce foul odours that have a negative impact on the quality of life for the local residents [5].

The awareness, attitudes and behaviours of people in the community are crucial to the management of MSW [6]. Reasons for individual participation in management of MSW are related to environmental motivation, social pressures, attitudes and economic incentives [7]. Problems with MSW management have arisen recently in developing countries where there is a little history of environmental awareness education [8] and where many members of the community are illiterate and unaware of the problem of solid waste accumulation [9]. The aim of this study was to determine the impact of a health education intervention on community knowledge, attitudes and behaviours concerning MSW management in Al Ghobeiry, Beirut.

\section{Methods}

\section{Study design}

This was a randomized semi-controlled intervention study in which subjects were prospectively and randomly assigned to an intervention or control group, with the intervention being a health education session.

\section{Sample}

A sample of 320 subjects was randomly selected from the inhabitants of $\mathrm{Al}$ Ghobeiry in the south Beirut suburbs during 2002. According to the relevant municipality report, the inhabitants of the area under investigation were about 1500 families that had come from different Lebanese ethnic and religious groups after the Lebanese war and from different socioeconomic strata. These families were characterized by a low income in comparison with other areas of Al Ghobeiry and a large number of scavengers living in the area [10]. Based on a study showing that $29.5 \%$ of women in Al Hermel city of Beqaa were aware about the disadvantages of solid waste, the minimum sample size was estimated as 320 with $95 \%$ confidence interval and 5\% precision [11].

Subjects were randomly selected from the list of households provided by the municipality with a geographical map. The subjects were the housewives resident at the selected family households or in some cases unmarried male workers who lived on their own [10]. The participants were informed about the study, the main objective and the programme of health education from a municipality advertisement and written informed consent was obtained from all those willing to enter the trial.

\section{Data collection}

Implementation of the study was divided into 3 phases: pre-test, intervention and post-test.

In the pre-test phase a questionnaire was completed by the 306 people who agreed to participate in the study. The questionnaire aimed to determine their knowledge, attitude and practices concerning MSW as baseline information and to develop the content of the health education intervention (see later). A team of 3 trained and experienced interviewers completed the questionnaires in door-to-door visits to the selected households. Each questionnaire took about 1 hour to complete and the interviewers finalized data collection within 1 month.

The second phase of the study started after the results of the pre-test had been analysed. Using the sealed envelope technique the sample was randomly divided into 2 equal groups: intervention and control groups (153 subjects in each). Subjects in the intervention group were given the health education programme (see later) that was developed, prepared and tested by the researchers based on the data collected in the first stage and on references and recommendations of the World Health Organization Regional Centre for Environmental Health Activities (CEHA). The control group did not participate in any of the health education activities.

Three months after the educational sessions (starting summer 2002), during which time both groups were presumed to be exposed to the same influencing factors, the interviewers started the third phase of the study. In the post-test phase the questionnaires were redistributed door-to-door and filled in by interview. This questionnaire included direct observations to detect behavioural modifications for both groups. As some of the subjects 
were unable to be contacted, only 296 recompleted the questionnaire.

\section{Questionnaire}

A structured questionnaire was prepared in Arabic language and reviewing and approved by a panel of specialists and experts from CEHA. It consisted of 4 sections:

- sociodemographic characteristics: 3 questions on participant's age, sex and educational level (close-ended);

- knowledge: 4 questions about problems caused by solid waste accumulation, diseases spread by solid waste and about hazardous wastes (openended questions);

- attitudes: a list of 15 questions assessed the inhabitant's opinion about to the importance of waste management, participation in management programmes in the community and community initiatives (closed questions, agree/disagree);

- practices: a list of 5 questions assessed how the inhabitant collected and eliminated household waste and reused solid waste (open-ended questions). At the same time direct observations were made about waste elimination practices using a checklist of items on collection, elimination, segregation and recycling.

\section{Health education programme}

The health education intervention was based on lectures and focus group discussion sessions under the supervision of 3 educators who were trained by the researcher. A training of trainers course was conducted during the first stage of the study with 10 volunteers with a health background ( 6 females and 4 males) who attended the course as a capacity building activity in order to prepare them for the community health education sessions. The course included knowledge about MSW based on CEHA materials and communication skills under the auspices of Al-Ghobeiri municipality and CEHA. After 2 weeks of training, 3 volunteer trainers were selected ( 2 females and 1 male), and were assigned to conduct sessions with 15-20 inhabitants (the male dealt with 2 groups of male subjects and 2 females each with 3 groups of female subjects).

A total of 8 sessions were conducted with the selected inhabitants over a 2 -week period. The teaching materials, e.g. educational brochures, posters and books, used in the educational sessions were prepared and approved by CEHA. Various educational activities were initiated in the lectures and discussion sessions which focused on: kinds of MSW, composition and elements of MSW, disadvantages and diseases related to bad MSW, ways of accumulation, segregation, separation, elimination, reusing and recycling of MSW, the role of community-based initiatives in MSW and hazardous waste.

\section{Data analysis}

The data collected were coded, categorized and tabulated as percentages and means. Comparisons were made across 3 groups: the total group (before intervention), the intervention group (after intervention) and control group (after intervention). Chi-squared tests were used for assessing the association between groups and to assess the impact of the intervention, using SPSS, version 12 .

\section{Results}

A total of 306 (95.6\%) subjects from the calculated sample accepted to participate in the study and completed the questionnaire in the first phase and 296 (92.5\%) completed the questionnaire in the third phase.

Table 1 shows the background characteristics of the groups before and after the intervention. Most of those who were responsible for dealing with MSW

\begin{tabular}{|c|c|c|c|c|c|c|c|c|}
\hline \multirow[t]{3}{*}{ Variable } & \multirow{2}{*}{\multicolumn{2}{|c|}{$\begin{array}{l}\text { Before (total group) } \\
\qquad(n=306)\end{array}$}} & \multirow{2}{*}{\multicolumn{2}{|c|}{$\begin{array}{l}\text { After (intervention group) } \\
\qquad(n=150)\end{array}$}} & \multirow{2}{*}{\multicolumn{2}{|c|}{$\begin{array}{l}\text { After (control group) } \\
\qquad(n=146)\end{array}$}} & \multicolumn{2}{|c|}{ Statistics } \\
\hline & & & & & & & \multirow[t]{2}{*}{$x^{2}$} & \multirow{2}{*}{$P$-value } \\
\hline & No. & $\%$ & No. & $\%$ & No. & $\%$ & & \\
\hline \multicolumn{9}{|l|}{ Sex } \\
\hline Male & 86 & 28.1 & 43 & 28.7 & 46 & 31.5 & 0.16 & 0.68 \\
\hline Female & 220 & 71.9 & 107 & 71.3 & 100 & 68.5 & 0.16 & 0.68 \\
\hline \multicolumn{9}{|l|}{ Age (years) } \\
\hline$<20$ & 43 & 14.1 & 23 & 15.3 & 21 & 14.4 & 0.0 & 1.0 \\
\hline $20-30$ & 99 & 32.4 & 45 & 30.0 & 44 & 30.1 & 0.01 & 0.92 \\
\hline $31-40$ & 63 & 20.6 & 32 & 21.3 & 30 & 20.5 & 0.02 & 0.88 \\
\hline$>40$ & 101 & 33.0 & 50 & 33.3 & 51 & 34.9 & 0.03 & 0.86 \\
\hline \multicolumn{9}{|l|}{ Education level } \\
\hline No education & 73 & 23.9 & 39 & 26.0 & 42 & 28.8 & 0.16 & 0.68 \\
\hline Secondary & 195 & 63.7 & 92 & 61.3 & 84 & 57.5 & 0.3 & 0.58 \\
\hline University & 38 & 12.4 & 19 & 12.7 & 20 & 13.7 & 0.01 & 0.92 \\
\hline
\end{tabular}


were female $(71.9 \%)$, a majority were aged less than 40 years old and with secondary level education (63.7\%), although there was also a high proportion of uneducated subjects (23.6\%). There were no significant differences in the distribution of the variables sex, age and educational level between the groups before the intervention (total group) and after the intervention (intervention and control groups) (Table 1).

Responses to the knowledge questions about handling MSW are shown in the Table 2. The percentage of participants scoring correctly in the intervention group (after intervention) was significantly higher for all knowledge items compared with the control group (after intervention) and with the total group (before intervention) (all $P<$ 0.005 ). Before the intervention only $10.5 \%$ of participants saw water pollution as a problem caused by MSW accumulation and this increased to 61.3\% after the intervention (versus $16.4 \%$ for the control group). Few people (3.3\%) thought gastroenteritis was a possible kind of disease spread but this increased to $80.7 \%$ versus $8.9 \%$ in the control group. Medical waste was not seen as a kind of hazardous waste (0.7 $\%)$ until after the intervention, when 91.3\% recognised it as a problem. Soil contamination by hazardous waste was only recognized by $2.0 \%$ before the intervention but by $90.7 \%$ after it (versus $6.2 \%$ of the control group).

Table 3 shows the percentage of respondents with positive answers to the questions about attitudes to handling solid waste (combining agreed and strongly agreed responses). There was a significant difference between groups before and after intervention and between intervention and control groups (all $\mathrm{P}<0.005)$. Before the intervention $90.8 \%$ of participants agreed that "Waste accumulation anywhere away from home does not lead to the spread of diseases", compared with $12.0 \%$ after the intervention (remaining at $92.8 \%$ among the controls). Those agreeing that collection of waste in closed container in the house prevents diseases rose from $47.7 \%$ before to $91.3 \%$ after the intervention. The statement "All family members can participate in reducing and reusing solid waste" was supported by only $5.8 \%$ before the intervention but $90.6 \%$ afterwards.

Table 4 shows positive responses to the behaviour questions about solid waste. Calculation of the association between the variables showed that there was a significant difference between the answers before and after the intervention and between the intervention and control groups $(P<0.005$ in all cases $)$. The proportion of participants reporting that they collected household waste in a bag inside a closed container rose from $19.9 \%$ before to $89.3 \%$ after the intervention (versus $20.5 \%$ in the control group). Similarly removing household waste by placing it in the street when the bag was full fell from $52.9 \%$ to $6.0 \%$ (versus $52.1 \%$ the control group), and the percentages separating and reusing different kinds of solid waste rose from between $0.6 \%$ and $3.9 \%$ before the intervention to between $86.7 \%$ and 95.3\% after it, but remained low among the control group (between $0.7 \%$ and $4.8 \%)$

Behaviour change towards MSW led to following observed changes: reusing of waste material by collecting and separating the paper, metals, glass, plastic, batteries; reduction in the amount of plastic bags used and their replacement by canvas bags; house-to-house solid waste collection organized by the community; and assigning different colour codes to the litter bins to ease the waste separation process and therefore prevent mix-up of plastics, metals, hazardous and medical wastes.

\section{Discussion}

The risk of unhealthy disposal of solid waste is an important issue in many societies, and recycling is considered as a solution for managing solid wastes [12]. The current legislation systems and waste management practices in many developing countries require numerous improvements and modifications. It is argued that such changes need to be accompanied by a community environmental education programme designed to improve citizens' knowledge, attitudes and behaviour $[13,14]$.

The results of our study showed that around $72 \%$ of the population sample were female. Women, as homemakers, can play a pivotal role in MSW in organizing waste collection campaigns and other activities related to MSW and helping to motivate other household members towards spreading awareness of good MSW. The important role of women in MSW has been shown in other literatures [15]. Also a large percentage of our participants were illiterate and this showed that to increase awareness about MSW information sources need to be adapted to suit all educational levels, for example using audiovisual media rather than books and brochures. Decision-makers need to take this issue into consideration when preparing television programmes, radio or any related activity. A previous study argued that raising awareness and health education via printed materials was not as effective as using modern promotional technologies [16].

Responses to the knowledge section of our questionnaire showed low awareness among $\mathrm{Al}$ Gobeiry city inhabitants about solid waste problems before the intervention. For example only 10.5\% of the participants thought that water pollution could be a problem caused by solid waste accumulation, only $3.2 \%$ knew about the risk of spreading gastroenteritis, $0.6 \%$ recognized medical waste as a type of hazardous waste and $1.9 \%$ that soil contamination was a problem caused by hazardous waste. A similar study in Yazd, Islamic Republic of Iran about MSW showed that knowledge was low among $34.0 \%$ of males and $51.4 \%$ of females [12]. The results 


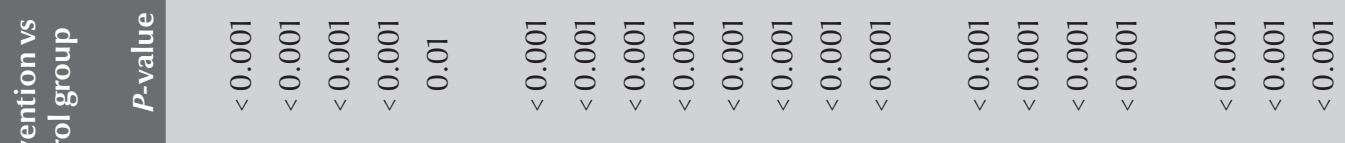

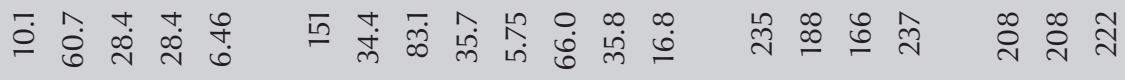

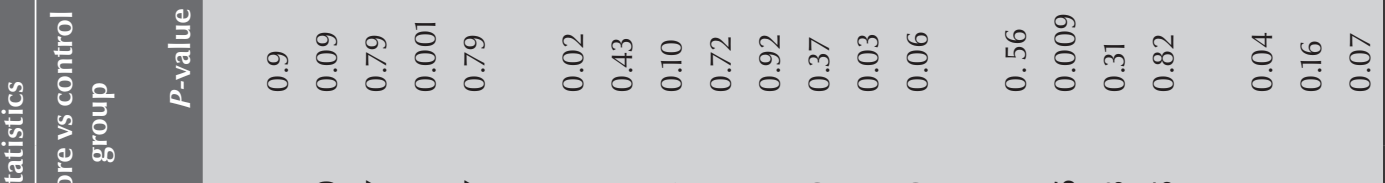

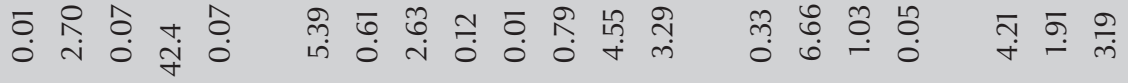

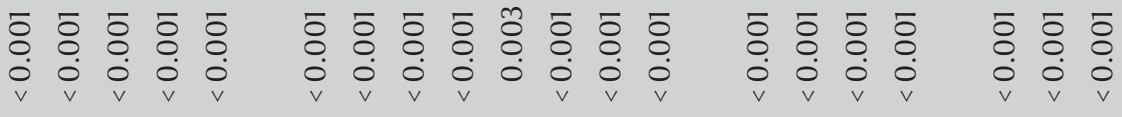

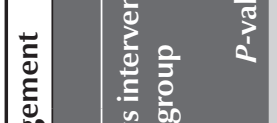

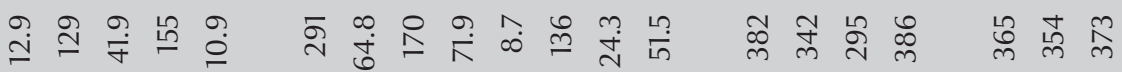

난

ㅎํ유

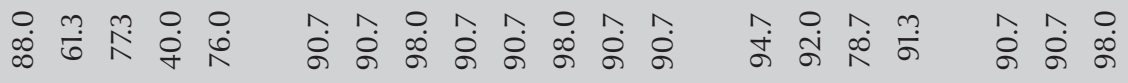

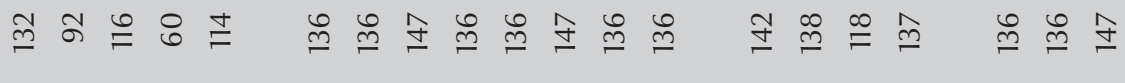

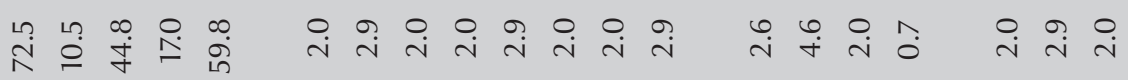

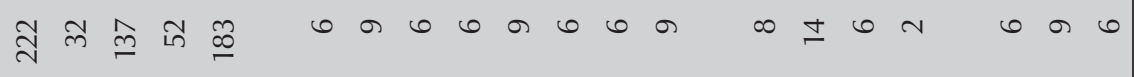

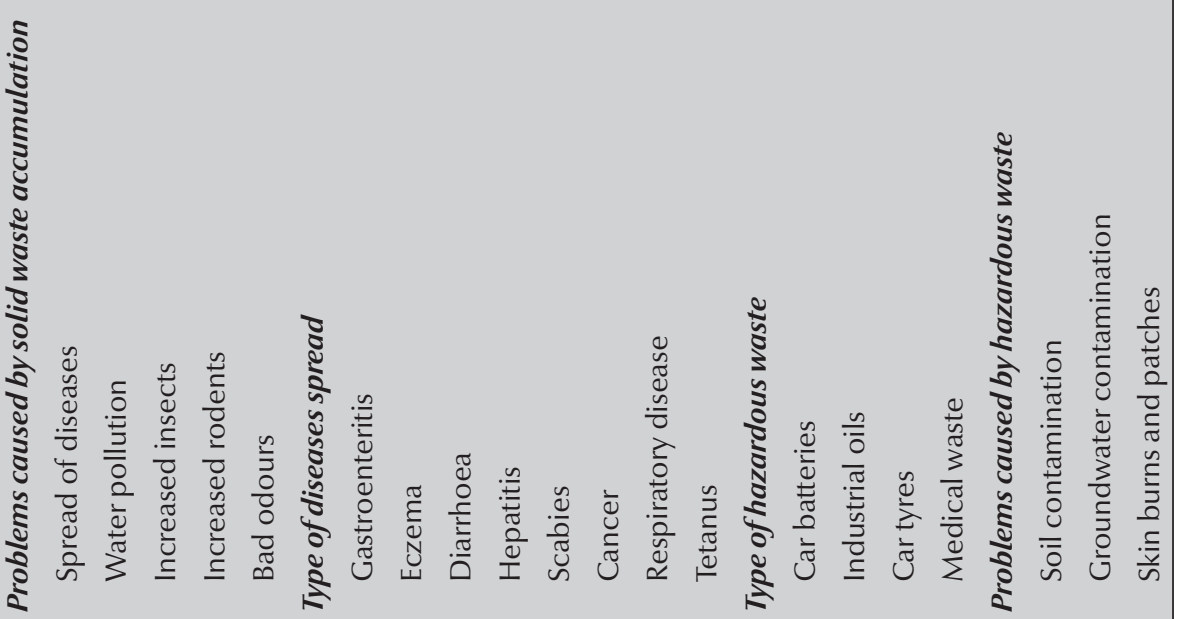




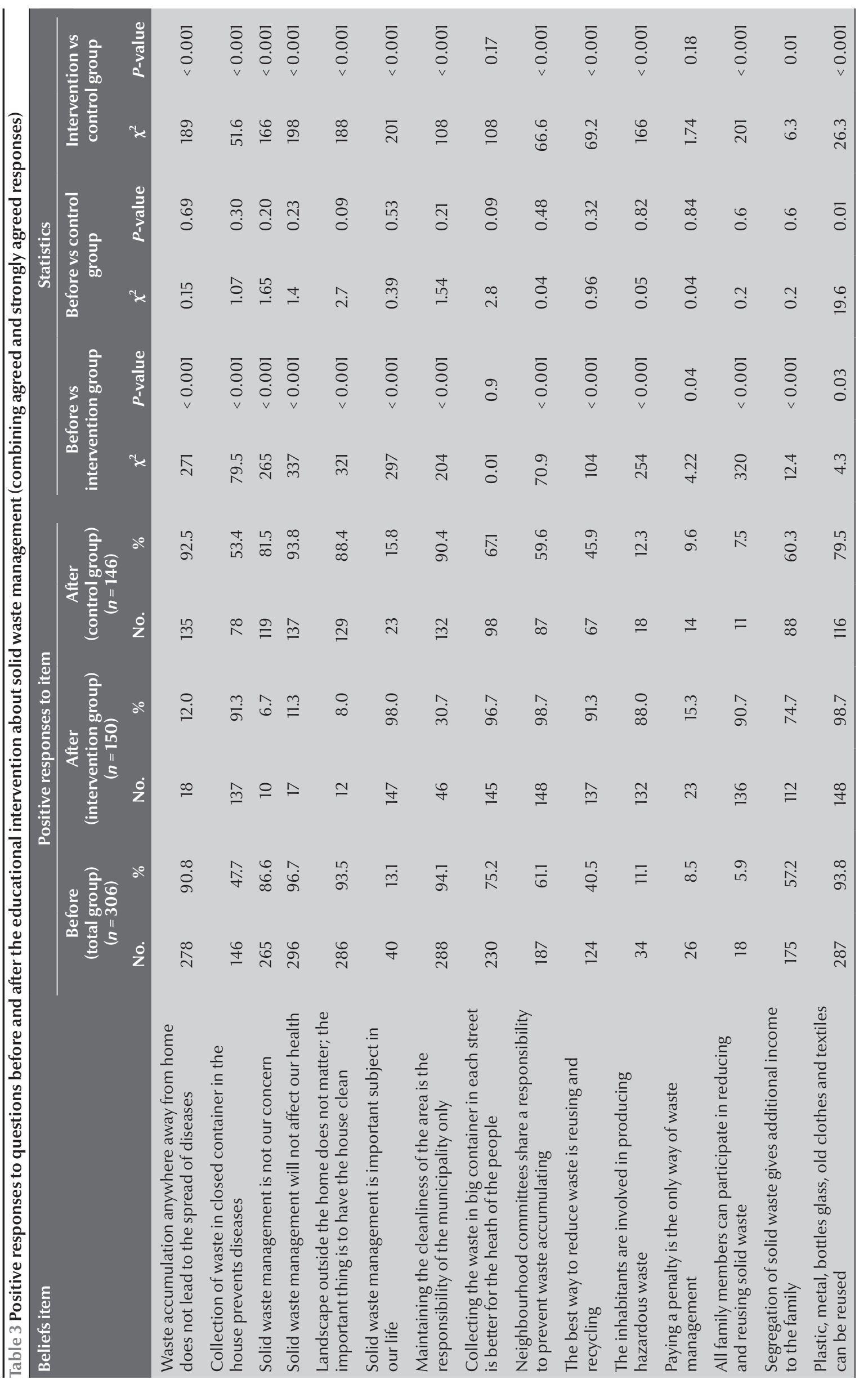




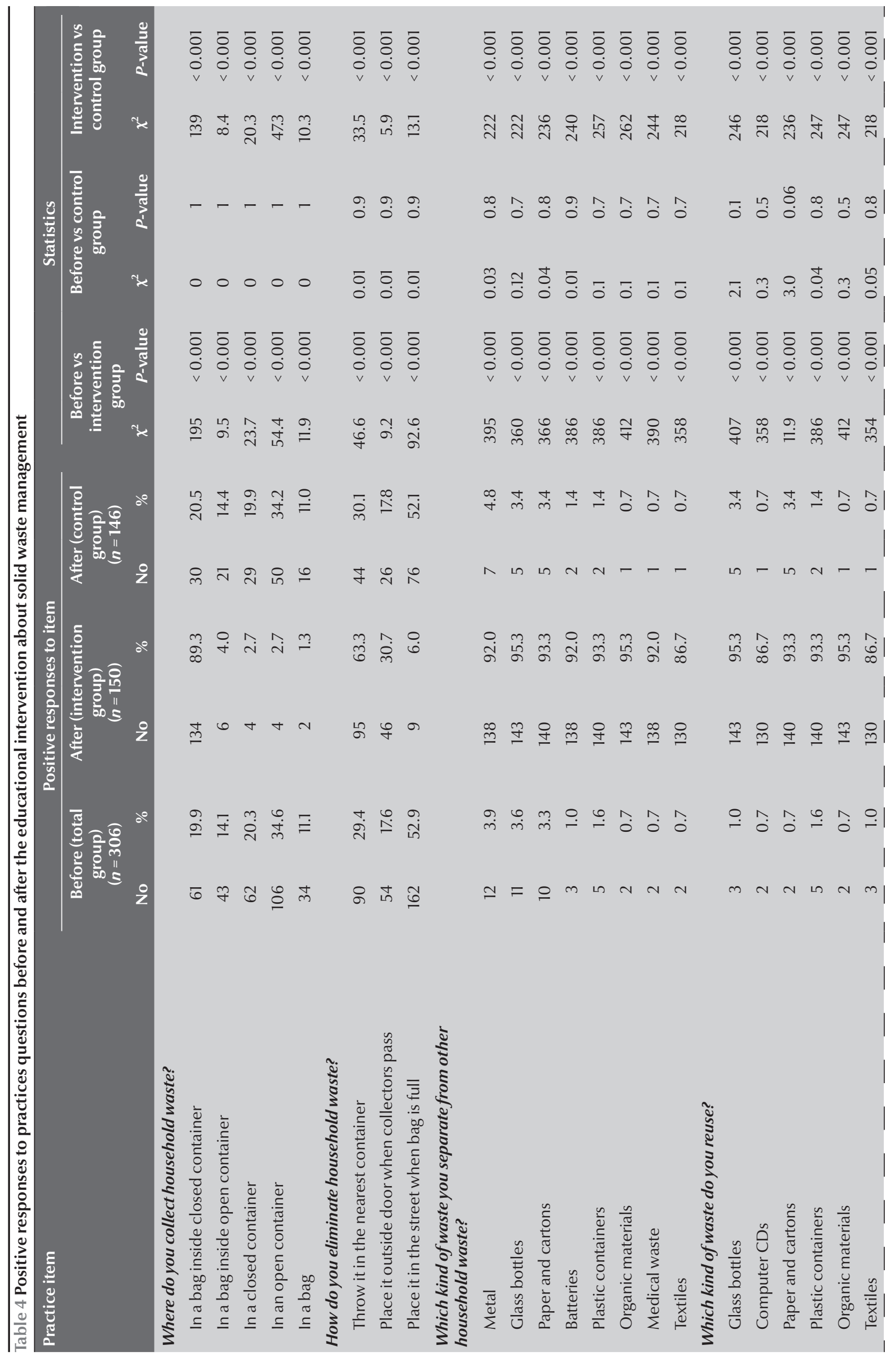




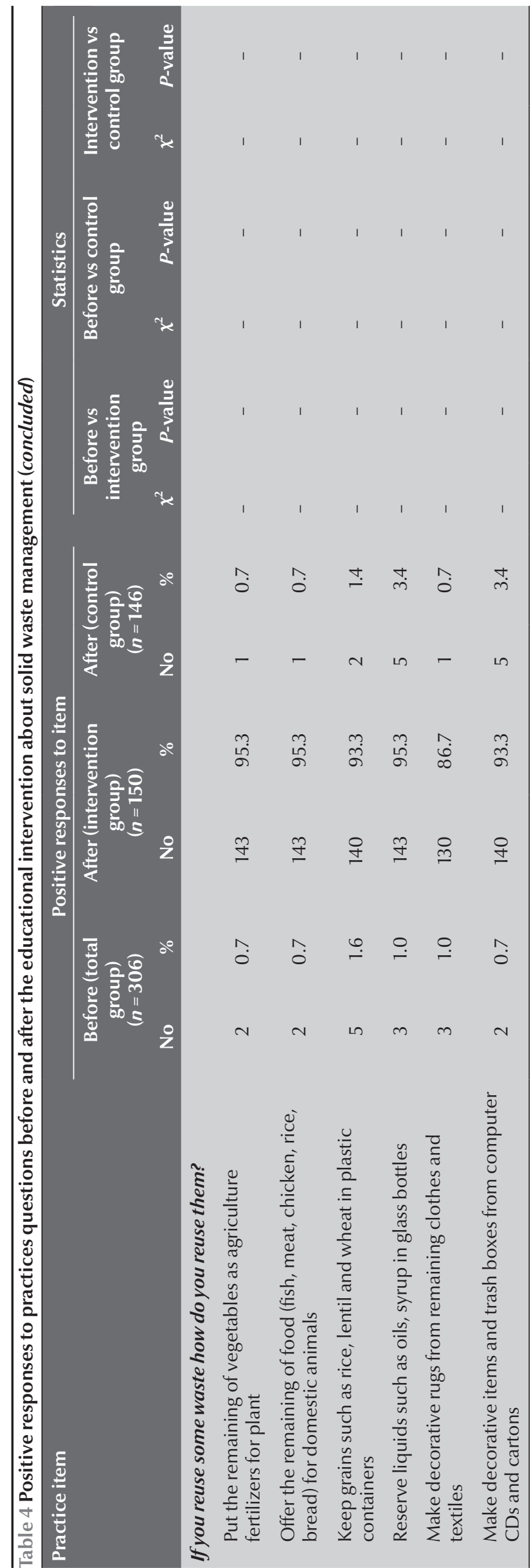

of our study also showed that the attitudes and practices about waste problems were poor among the majority of the inhabitants before the intervention and they had incorrect and inappropriate behaviours towards MSW.

After participating in the health education sessions the intervention group showed highly significant improvements in all items of knowledge. Increases in knowledge about types of diseases spread and types of hazardous waste were particularly pronounced; for example respondents' awareness of hazardous medical waste rose from $0.6 \%$ to $91.4 \%$. A study of home-generated medical waste in Mauritius reported that a large proportion of medical waste arising from the domestic environment joined the common MSW stream and ended up in landfills [17]. The authors called for "a national policy on medical waste management be urgently implemented, proper training of waste haulers be offered and education campaign be carried out to sensitize the general public on safe disposal of medical waste" [17].

The health education sessions in our study were also followed by significant increases in awareness as illustrated by changes in attitudes towards MSW. For example before the intervention $90.8 \%$ did not agree that "waste accumulation anywhere away from home does not lead to the spread of diseases" and this fell to $12.0 \%$ after the intervention. A study in Accra found that the majority of households stored their waste in open containers and plastic bags in the home, which was associated with the presence of houseflies in the kitchen, which in turn was correlated with the incidence of childhood diarrhoea [18]. There were also very marked changes in practices of handling MSW in our study. For example at the start of the study $34.6 \%$ of the participants stored their waste at home in an open container. After intervention this decreased to $2.6 \%$ in the intervention group and remained at $34.2 \%$ in the control group. We also showed a huge improvement in reusing and segregation of MSW among participants after the intervention. Before the intervention only 2 or 3 of the respondents $(<1 \%)$ were recycling materials such as bottles and cartons, whereas after the educational sessions between $89 \%-95 \%$ reported recycling these items. This agrees with another study which showed the importance of recycling and segregation. In Agunwamba's cost-analysis in Nigeria the lowest cost option involved encouraging individual households to separate their recyclables, which were bought by scavengers [19].

Finally, our researcher observed many innovations that were introduced after the heath education, for example the old textile waste was used to produce beautiful rugs, the plastic tyres were used as coloured container for plants and swings for children in parks and fairs, dry seeds which usually were considered an useless waste were used 
for decorating frames and bowls and the organic waste was used as a soil base for growing plants, etc. The impact of health education also revealed communitybased initiatives which were seen in an increased participation by people in cleaning campaigns and voluntary work in all the municipality activities.

In conclusion, a health education programme about MSW based on lectures and discussion sessions was followed by a significant improvement in the knowledge, attitudes and practices towards waste management among participants and led to many reforms in reusing and managing solid waste within this community in south Beirut.

\section{References}

1. Chalmin P, Gaillochet C. From waste to resource: an abstract of the 2006 world waste survey. Paris, Veolia Environmental Services, 2009.

2. Towards a green economy: pathways to sustainable development and poverty eradication. Nairobi, United Nations Environment Programme, 2011.

3. Country report on solid waste management. Lebanon. Tunis, Regional Solid Waste Management Project in Mashreq and Maghreb Countries/GTZ-ERM-GKW/ World Bank/Mediterranean Environmental Technical Assistance Programme, 2004.

4. Green jobs assessment in Lebanon. Preliminary assessment waste management. Geneva, International Labour Office/United Nations Development Fund, 2011.

5. State and trends of the Lebanese environment. Beirut, Ministry of Environment, 2011.

6. Yadav M. Hospital waste-a major problem. JK Practitioner, 1998, 8:276-282.

7. Bartlett C. Stormwater knowledge, attitude and behaviors: a 2005 survey of North Carolina residents. Sacramento, California, Stormwater Unit, Division of Environmental Analysis, 2005 (http://www.ncstormwater.org/pdfs/stormwater_survey_12506.pdf, accessed 5 May 2012).

8. Ojeda BS, Armijo VC, Ramirez BM. The potential of recycling household waste: A case study from Mexicali, Mexico. Environment and Urbanization, 2000, 12:163-173.

9. Li S. Recycling behaviour under China's social and economic transition: the case of metropolitan Wuhan. Environment and Behavior, 2003, 35:784-801.

10. Municipality of AlGhobeiri, annual report, population and determinants distribution. 1995.

11. Final report of public health, study on community and family assessment in AlHermel, Bequaa, Lebanon. Beirut, United Nations Population Fund, 1988.
12. Ehrampoush H, Baghianimoghadam MH. Survey of knowledge, attitude and practice of Yazd University of Medical Sciences students about solid wastes disposal and recycling. Iranian Journal of Environmental Health, Science and Engineering, 2005, 2(2):26-30.

13. McGarity AE, Wojcik WA Solid waste management in Poland. In: Proceedings of the 17th international conference on solid waste technology and management, 21-21 October 2000. Philadelphia, Pennsylvania, Solid Waste Technology and Management Press, 2000:10-56.

14. Grodzinska-Jurczak MS. Management of industrial and municipal solid wastes in Poland. Resources, Conservation and Recycling, 2001, 32:85-103.

15. Contribution of women in solid waste management. Sri Lanka, Wastewater Agriculture and Sanitation for Poverty Alleviation, 2009.

16. Pawlowski ZS et al. Impact of health education on knowledge and prevention behavior for congenital toxoplasmosis: the experience in Poznań, Poland. Health Education Research, 2001, 16:493-502.

17. Subratty AH, Nathire MH. A survey on home generated medical waste in Mauritius. International Journal of Environmental Health Research, 2005, 15:45-52.

18. Boadi RO, Kuitunen M. Environmental and health impacts of household solid waste handling and disposal practices in third world cities: the case of the Accra metropolitan area, Ghana, Journal of Environmental Health, 2005, 68(4):32-36.

19. Agunwamba JC. Analysis of scavengers' activities and recycling in some cities of Nigeria. Environmental Management, 2003, 32(1):116-127. 